Check for updates

Cite this: Mater. Adv., 2020,

1, 310

Received 6th March 2020

Accepted 14th May 2020

DOI: $10.1039 / \mathrm{d} 0 \mathrm{ma} 00083 \mathrm{c}$

rsc.li/materials-advances

\title{
Metal organic frameworks for adsorption-based separation of fluorocompounds: a review
}

\begin{abstract}
Darshika K. J. A. Wanigarathna, ${ }^{\text {abcd }}$ Jiajian Gao (D) ${ }^{c}$ and Bin Liu (D) *abc
Fluorocompounds have important applications in industry, but they are environmentally unfriendly, can cause ozone depletion and contribute to global warming with long atmospheric lifetime and high global warming potential. Hence, reclamation of used fluorocompounds via energy efficient adsorption-based capture and separation will greatly contribute to controlling their environmental release and reduce their impact on the environment. Among the various types of adsorbents, emerging metal organic frameworks (MOFs) display excellent gas adsorption performances. In this review article, we discuss the specific structural, physical and chemical properties of MOFs that lead to the high fluorocompound adsorption capacity, selectivity and regenerability. To rationalize the extremely high adsorption capacities and excellent selectivities, the interactions of various fluorocompound molecules with different functional moieties in MOFs are further discussed. Last but not least, we also highlight the key issues that require further research for industrial scale application of MOFs for fluorocompound separation. Ultimately, we hope that our work will stimulate more studies to understand the fluorocompound adsorption in MOFs in order to design high performance MOFs with optimum adsorption capacity and selectivity for fluorocompound capture and separation.
\end{abstract}

\section{Introduction}

With rising concerns over global warming and climate change, great attention has been paid to minimizing the use and emission of greenhouse gases. Chlorofluorocarbons (CFCs), hydrochlorofluorocarbons (HCFCs), hydrofluorocarbons (HFCs), perfluorocarbons (PFCs) and other fluorinated compounds are widely used as refrigerants, solvents, fluoropolymers etc. in various industries. ${ }^{1,2}$ But at the same time, these fluorocompounds have attracted worldwide attention due to their adverse effects on the environment. $^{3,4}$ Most of the fluorocompounds are greenhouse gases with very high global warming potential (GWP) and some can even cause ozone layer depletion. ${ }^{5,6}$ Therefore, the usage and environmental emission of these compounds are strictly controlled in most countries.

The most frequently used method for reclamation of used fluorocompounds on a large scale is cryogenic separation i.e., liquefaction followed by distillation. ${ }^{7}$ However, in many cases,

\footnotetext{
${ }^{a}$ Interdisciplinary Graduate School, Nanyang Technological University, 50 Nanyang Avenue, Singapore 639798, Singapore

${ }^{b}$ Residues \& Resource Reclamation Centre, Nanyang Environment and Water Research Institute, CleanTech One, Nanyang Technological University, Singapore 637141, Singapore

${ }^{c}$ School of Chemical and Biomedical Engineering, Nanyang Technological University, 62 Nanyang Drive, Singapore 637459, Singapore

${ }^{d}$ Department of Engineering Technology, Faculty of Technology, University of Sri Jayewardenepura, Gangodawila, Nugegoda 10250, Sri Lanka
}

the purity of fluorocompounds separated after distillation cannot immediately meet the industrial application standards. Most of the refrigerant blends are azeotropic mixtures, which are extremely difficult to separate based on cryogenic separation. Furthermore, cryogenic separation is an energyintensive process. ${ }^{8}$ On the other hand, adsorption based gas separation is a well-established technology that is more energy efficient although the proper selection of a suitable adsorbent is crucial.

Metal organic frameworks (MOFs) are a novel class of hybrid materials, which are composed of metal units attached together covalently by organic linkers to form architecturally stable structures with permeant porosity. So far, MOFs have shown enormous potential applications in gas storage, ${ }^{9,10}$ separation, ${ }^{11-16}$ catalysis, ${ }^{17-20}$ sensing, ${ }^{21}$ drug delivery etc. For gas adsorption and separation, via the interplay of both metal-containing clusters and organic linkers, the pore size of MOFs can be tuned to induce steric effects, while their pore surfaces can be functionalized to enhance their different interactions with gas molecules during equilibrium separation. ${ }^{22}$ Although the gas adsorption and separation potentials of MOFs are extensively studied, fluorocompound adsorption and separation has been mostly limited to conventional porous adsorbents such as activated carbon, zeolite and silica. Until now, the reported adsorption and adsorption-based separations of fluorocompounds are aimed at removal of byproducts during the production of different fluorocompounds, in adsorption based heating and 
cooling systems, and rarely on recycling of used fluorocompounds. In this review article, we discuss the specific structural, physical and chemical properties of MOFs that lead to high fluorocompound adsorption capacities, selectivities and thermal/ chemical/moisture stabilities. Ultimately, we hope that our work will stimulate more studies to understand the fluorocompound adsorption in MOFs in order to design high performance MOFs with optimum adsorption capacity and selectivity for fluorocompound capture and separation.

We categorized the fluorocompounds into two groups: (1) PFCs that are used in the semiconductor industry and as electric insulators and (2) CFCs, HCFCs and HFCs that are used in refrigeration and air conditioning systems.

\section{Adsorption and adsorption-based separation of PFCs $\left(\mathrm{SF}_{6}, \mathrm{CF}_{4}, \mathrm{C}_{2} \mathrm{~F}_{6}\right.$ and etc.)}

PFCs are critical to the current semiconductor manufacturing methods because they possess unique characteristics when used in a plasma that currently cannot be duplicated by other alternatives. The semiconductor industry uses PFCs such as $\mathrm{CF}_{4}, \mathrm{C}_{2} \mathrm{~F}_{6}, \mathrm{C}_{3} \mathrm{~F}_{8}, \mathrm{SF}_{6}, \mathrm{CHF}_{3}$ (HFC-23) and $\mathrm{NF}_{3}$ in two important production processes - plasma etching thin films and plasma

Table 1 Global warming potential of various PFCs

\begin{tabular}{lcc}
\hline $\begin{array}{l}\text { Chemical } \\
\text { formula }\end{array}$ & $\begin{array}{l}\text { Atmospheric } \\
\text { lifetime (years) }\end{array}$ & $\begin{array}{l}\text { Global warming potential } \\
(100 \text {-year time horizon) }\end{array}$ \\
\hline $\mathrm{CHF}_{3}$ & 264 & 11700 \\
$\mathrm{CF}_{4}$ & 50000 & 6500 \\
$\mathrm{C}_{2} \mathrm{~F}_{6}$ & 10000 & 9200 \\
$\mathrm{C}_{3} \mathrm{~F}_{8}$ & 2600 & 7000 \\
$\mathrm{SF}_{6}$ & 3200 & 23900 \\
$\mathrm{NF}_{3}$ & 740 & 8000
\end{tabular}

cleaning chemical vapor deposition (CVD) tool chambers. The vent gas from the semiconductor plasma etching process often contains unreacted $\mathrm{CF}_{4}$ and/or $\mathrm{C}_{2} \mathrm{~F}_{6}$, and other PFCs such as $\mathrm{SF}_{6}, \mathrm{NF}_{3}$, and $\mathrm{CHF}_{3}$ as well as $\mathrm{N}_{2}$. Other than in the semiconductor industry, $\mathrm{SF}_{6}$ and $\mathrm{SF}_{6} / \mathrm{N}_{2}$ mixtures are being widely used in medium and high voltage switchgears and gas insulated transmission lines thanks to their dielectric strength and excellent insulating properties. However, these PFCs are among the most potent and longest-lasting type of greenhouse gases (Table 1).

The major abatement technologies of PFCs can be divided into four categories: thermal destruction, chemical conversion, plasma destruction, and recovery/reclamation. ${ }^{23}$ Though the PFCs have excellent chemical stability, the major issue associated with the recovery/recycling and reuse of PFCs, especially in the semiconductor manufacturing processes, is that the recycled PFC substances should have ultrahigh purity to prevent any unwanted contamination to silicon. ${ }^{24}$

Table 2 lists the reported adsorption capacities (at 1 bar and $298 \mathrm{~K}$ ) of $\mathrm{SF}_{6}, \mathrm{CF}_{4}$ and $\mathrm{C}_{2} \mathrm{~F}_{6}$ in various types of MOFs and other conventional adsorbents. So far, the highest adsorption capacity of $\mathrm{SF}_{6}$ is reported in Mg-MOF-74 $\left(6 \mathrm{mmol} \mathrm{g}^{-1}\right)$ followed by Co-MOF-74 $\left(5.2 \mathrm{mmol} \mathrm{g}^{-1}\right), \mathrm{Cu}_{3}(\mathrm{BTC})_{2}\left(4.78 \mathrm{mmol} \mathrm{g}^{-1}\right)$ and Zn-MOF-74 $\left(3.8 \mathrm{mmol} \mathrm{g}^{-1}\right)$. It is interesting to note that all these MOFs have coordinatively unsaturated metal sites (CUS). The unsaturated metal centers in the one-dimensional hexagonal channels (11 A diameter) of isostructural Mg-MOF-74, Co-MOF-74 and Zn-MOF-74 are responsible for their high $\mathrm{SF}_{6}$ adsorption capacity. The adsorption capacities of mesoporous MOFs (MIL-101 and DUT-9) under atmospheric conditions (2.01 $\mathrm{mmol} \mathrm{g}^{-1}$ for MIL-101 and $2.32 \mathrm{mmol} \mathrm{g}^{-1}$ for DUT-9) are not as high as that on the MOFs with CUS, but at high pressures (18 bar), they exhibit higher $\mathrm{SF}_{6}$ uptake of $12.3 \mathrm{mmol} \mathrm{g}^{-1}$, which is a characteristic of the MOF with larger surface area and pore volume. Other than the ones mentioned above, several other MOFs $\left(\mathrm{Co}_{2}(1,4-\mathrm{bdc})_{2}(\mathrm{dabco})\right.$

Table 2 Adsorption capacities of various PFCs and $\mathrm{N}_{2}$ in MOFs at 1 bar and $298 \mathrm{~K}$

\begin{tabular}{|c|c|c|c|c|c|c|c|}
\hline \multirow[b]{2}{*}{ Adsorbent } & \multirow{2}{*}{$\begin{array}{l}\text { BET surface } \\
\text { area }\left(\mathrm{m}^{2} \mathrm{~g}^{-1}\right)\end{array}$} & \multirow{2}{*}{$\begin{array}{l}\text { Total pore } \\
\text { volume }\left(\mathrm{cm}^{3} \mathrm{~g}^{-1}\right)\end{array}$} & \multicolumn{4}{|c|}{ Adsorption amount $\left(\mathrm{mmol} \mathrm{g}^{-1}\right)$} & \multirow[b]{2}{*}{ Ref. } \\
\hline & & & $\mathrm{SF}_{6}$ & $\mathrm{CF}_{4}$ & $\mathrm{C}_{2} \mathrm{~F}_{6}$ & $\mathrm{~N}_{2}$ & \\
\hline Mg-MOF-74 & 1631 & - & 6.3 & & & 1.05 & 25 \\
\hline Co-MOF-74 & 1219 & - & 5.2 & & & 0.63 & 25 \\
\hline $\mathrm{Cu}_{3}(\mathrm{BTC})_{2}$ & - & 0.8 & 4.78 & 1.16 & & & $26-28$ \\
\hline Zn-MOF-74 & 992 & - & 3.8 & & & 0.32 & 25 \\
\hline $\mathrm{Co}_{2}(1,4-\mathrm{bdc})_{2}(\mathrm{dabco})$ & - & 08 & 3.39 & 0.71 & & & 26 \\
\hline $\mathrm{Zn}_{4} \mathrm{O}(\mathrm{btb})$ & - & 0.9 & 3.12 & 0.49 & & & 26 \\
\hline MIL-100(Fe) & $1619^{a}$ & $0.9 / 0.82^{a}$ & $2.95 / 1.6^{a}$ & 0.54 & & $0.13^{a}$ & 26 and 29 \\
\hline $\mathrm{Zn}_{4} \mathrm{O}(\mathrm{dmcpz})_{3}$ & - & 0.5 & 2.54 & 1.87 & & & 26 \\
\hline DUT-8(Ni) & - & 0.9 & Very low & Very low & & & 26 \\
\hline DUT-9 & - & 1.8 & 2.32 & 0.45 & & & 26 \\
\hline MIL-101 & 2674 & 1.5 & 2.01 & 0.54 & & & 26 and 30 \\
\hline MOFF-5 & 2445 & - & 1.74 & 0.09 & & & 31 \\
\hline UiO-66(Zr) & 1333 & - & 1.45 & & & 0.21 & 29 and 32 \\
\hline 13X zeolite ${ }^{b}$ & 721 & - & 1.75 & 0.76 & 1.55 & 0.24 & $32-34$ \\
\hline $5 \mathrm{~A}$ zeolite ${ }^{c}$ & 552 & 0.2 & Very low $(<0.1)$ & 0.55 & - & 0.26 & 33 and 35 \\
\hline Activated carbon ${ }^{c}$ & 633 & 0.23 & & 0.72 & 1.26 & 0.25 & 33 \\
\hline Silica gel ${ }^{c}$ & 584 & 0.21 & & & 0.5 & 0.04 & 33 \\
\hline
\end{tabular}

${ }^{a}$ On granular MIL-100(Fe). ${ }^{b}$ At $293 \mathrm{~K} .{ }^{c}$ At $303 \mathrm{~K}$. 
Table 3 Physical properties of various PFCs ${ }^{36}$

\begin{tabular}{lllll}
\hline PFC & $\begin{array}{l}\text { Kinetic } \\
\text { diameter/A }\end{array}$ & $\begin{array}{l}\text { Boiling } \\
\text { point/K }\end{array}$ & $\begin{array}{l}\text { Polarizability } \times \\
10^{25} \mathrm{~cm}^{-3}\end{array}$ & $\begin{array}{l}\text { Dipole moment } \times \\
10^{18} \mathrm{esu}^{-1} \mathrm{~cm}^{-1}\end{array}$ \\
\hline $\mathrm{CF}_{4}$ & 4.662 & 145.11 & 38.4 & 0 \\
$\mathrm{C}_{2} \mathrm{~F}_{6}$ & 5.10 & 195.21 & 68.2 & 0 \\
$\mathrm{SF}_{6}$ & 5.128 & 209.25 & 65.4 & 0 \\
$\mathrm{NF}_{3}$ & 3.62 & 144.11 & 36.2 & 0.235 \\
$\mathrm{~N}_{2}$ & 3.64 & 77.35 & 17.4 & 0
\end{tabular}

(3.39 $\left.\mathrm{mmol} \mathrm{g}^{-1}\right), \mathrm{Zn}_{4} \mathrm{O}(\mathrm{btb})\left(3.12 \mathrm{mmol} \mathrm{g}^{-1}\right.$ ), MIL-100(Fe) $\left.\left(2.94 \mathrm{mmol} \mathrm{g}^{-1}\right), \mathrm{Zn}_{4} \mathrm{O}(\mathrm{dmcpz})_{3}\left(2.54 \mathrm{mmol} \mathrm{g}^{-1}\right)\right)$ are reported with high $\mathrm{SF}_{6}$ adsorption capacities.

The main feature of the $\mathrm{SF}_{6}$ adsorption isotherm in $13 \mathrm{X}$ zeolite as compared to those in MOFs is the sharp increase of the uptake at the low-pressure region followed by saturation at around 3 bar. Because of this, though $13 \mathrm{X}$ zeolite has higher $\mathrm{SF}_{6}$ adsorption capacity than some MOFs, the working capacity between 0.1 and 1 bar becomes very low.

Interestingly, the adsorption of $\mathrm{CF}_{4}$ in both zeolites and MOFs is much lower as compared to that of $\mathrm{SF}_{6}$, which can be rationalized by their differences in polarizability (Table 3 ). The significant difference of $\mathrm{SF}_{6}$ and $\mathrm{CF}_{4}$ in adsorption capacity in MOFs suggests their possible equilibrium separation. However, to the best of our knowledge, separation of $\mathrm{SF}_{6} / \mathrm{CF}_{4}$ mixtures in MOFs or zeolites has not been reported in the literature.

Because of the important applications of $\mathrm{SF}_{6} / \mathrm{N}_{2}$ mixtures as insulators for electrical cables/equipment, $\mathrm{SF}_{6} / \mathrm{N}_{2}$ separation has become an industrially important goal. Among various MOFs and zeolites, UiO-66(Zr) shows the highest reported $\mathrm{SF}_{6} / \mathrm{N}_{2}$ selectivity of 74 (calculated using the Ideal Adsorption Solution Theory (IAST) at 1 bar and 293 K) (Fig. 1). The higher selectivity of UiO-66(Zr) can be explained by the stronger $\mathrm{SF}_{6}$ adsorption originating from the pore confinement effect of small pores $(8,11 \AA)$ of UiO-66(Zr) as compared to M-MOF-74, 13X zeolite and MIL-100(Fe). ${ }^{32}$ Relevant to the conditions in the plasma etching processes in the semiconductor industry, UiO-66(Zr) presents even higher selectivities (172) for diluted $\mathrm{SF}_{6}$ mixtures $(0.2 \%)$. Additionally, experimental breakthrough data further proves the high selectivity of UiO-66(Zr) for $\mathrm{SF}_{6} / \mathrm{N}_{2}$ separation. ${ }^{32}$ However, it should be noted that the adsorption capacity of $\mathrm{SF}_{6}$ in UiO-66(Zr) $\left(1.45 \mathrm{mmol} \mathrm{g}^{-1}\right)$ is much lower than that in other reported MOFs, whereas both adsorption capacity and selectivity are equally important to realize efficient gas separation. Among the isostructural M-MOF-74 (M= Mg, Co, Zn), the IAST-derived $\mathrm{SF}_{6} / \mathrm{N}_{2}$ separation selectivity is the highest for Zn-MOF-74, contradictory to their orders of $\mathrm{BET}$ surface area and $\mathrm{SF}_{6}$ adsorption capacity. ${ }^{25}$ The higher selectivity of Zn-MOF-74 may occur due to the relatively smaller adsorption amount of $\mathrm{N}_{2}$. Furthermore, Zn-MOF-74 outperforms the benchmark $13 \mathrm{X}$ zeolite in both adsorption capacity and selectivity. However, by analyzing the working capacity, selectivity and regeneration performances of these MOFs, Co-MOF-74 seems more suitable for $\mathrm{SF}_{6} / \mathrm{N}_{2}$ separation as it exhibits high working capacity $\left(1.96 \mathrm{mmol} \mathrm{g}^{-1}\right)$, selectivity (35) and regenerability (>80\%) via vacuum swing adsorption.
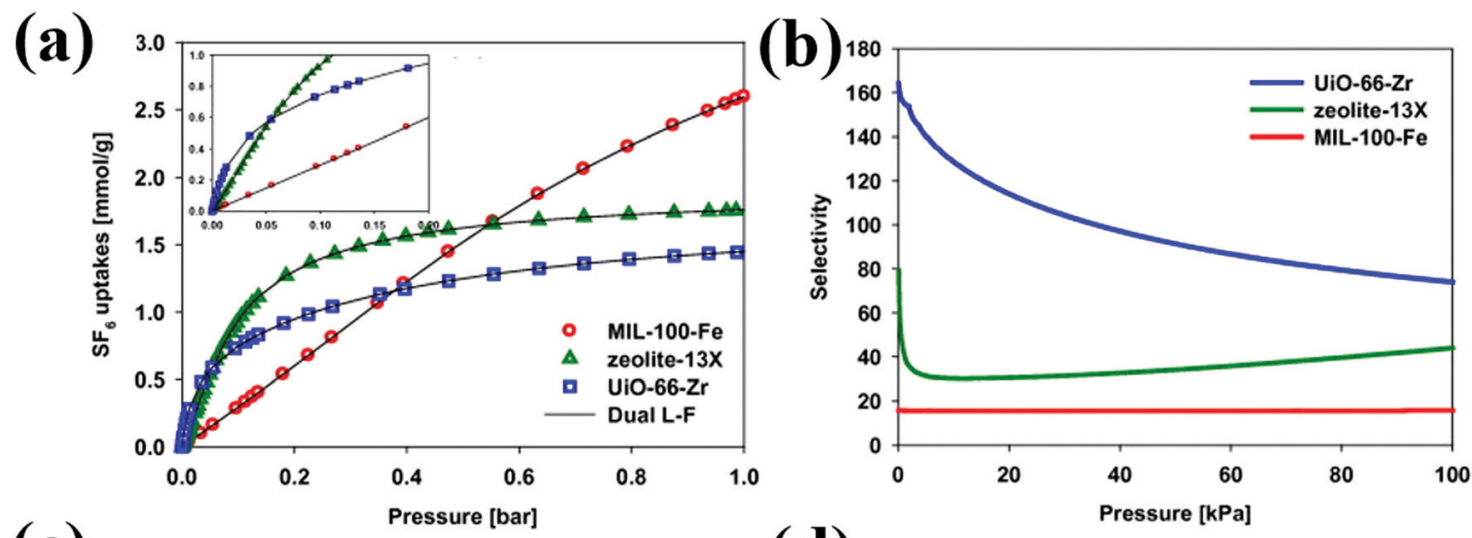

(c)

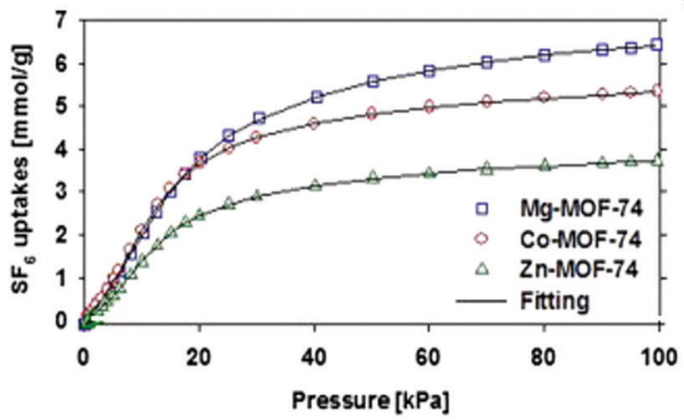

(d)

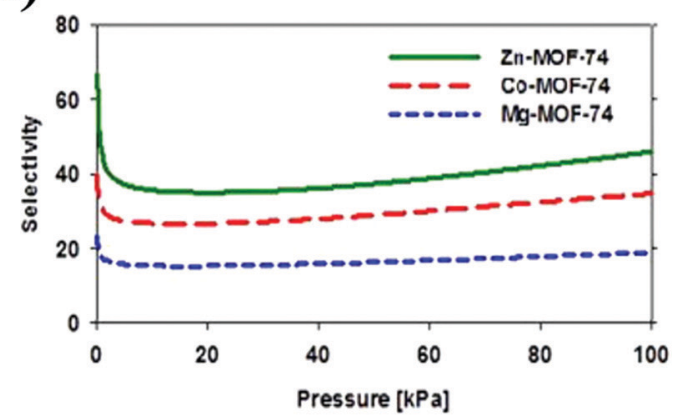

Fig. $1 \mathrm{SF}_{6}$ pure gas adsorption isotherms and selectivity calculated using IAST theory on (a) \& (b) MIL-100-Fe, 13X zeolite, and UiO-66(Zr); (c) $\&$ (d) M-MOF-74 (M = Mg, Co, Zn) at $298 \mathrm{~K}$, respectively. ${ }^{25,32}$ Reproduced from ref. 25 and 32 with permission from Elsevier. 


\section{Adsorption and adsorption-based separation of CFCs, HCFCs and HFCs (R13, R12, R22, R32, R125, $\mathrm{R} 134 \mathrm{a}$ and etc.)}

CFCs, HCFCs and HFCs are industrially important compounds especially in the air conditioning and refrigeration industry (Fig. 2 and Table 4). Driven by zero-ozone layer depletion and low global warming potential, a major fraction of the current refrigerant demand is fulfilled by HFCs. For example, R12 that was used in domestic refrigerators and mobile air conditioning systems is now being replaced by R134a. Also, R410A that is blended from R32 and R125 is now widely being used in residential air conditioning systems as a replacement for R22.

Recovery and reclamation of used fluorocompounds positively contributes to the environmental sustainability and at the same time provides an alternative channel to fulfill their increasing demands. Hence, planning and design of energy efficient adsorption-based fluorocompound reclamation processes becomes an urgent requirement. However, as an emerging adsorbent, utilization of MOFs for the separation of fluorocompounds requires a comprehensive study on the fluorocompound-MOF interactions.

Table 5 lists the reported adsorption capacities of R32, R22, R125, R134a and R12 fluorocarbon refrigerants in several adsorbents including MOFs, zeolite, activated carbon and silica. It is clear to notice the extremely high fluorocarbon adsorption capacity in MOFs as compared to that in conventional zeolite and silica.

$\mathrm{R} 22$ is a common fluorocarbon refrigerant that is widely used in residential air conditioning and refrigeration systems. The adsorption properties of R22 in various MOFs including MAF-X10 $\left[\mathrm{Zn}_{4} \mathrm{O}(\mathrm{bpz})_{2}(\mathrm{bdc})\right], \quad \mathrm{MAF}-\mathrm{X} 12 \quad\left[\mathrm{Zn}_{4} \mathrm{O}(\mathrm{bpz})_{2}(\mathrm{ndc})\right], \quad \mathrm{MAF}-\mathrm{X} 13$

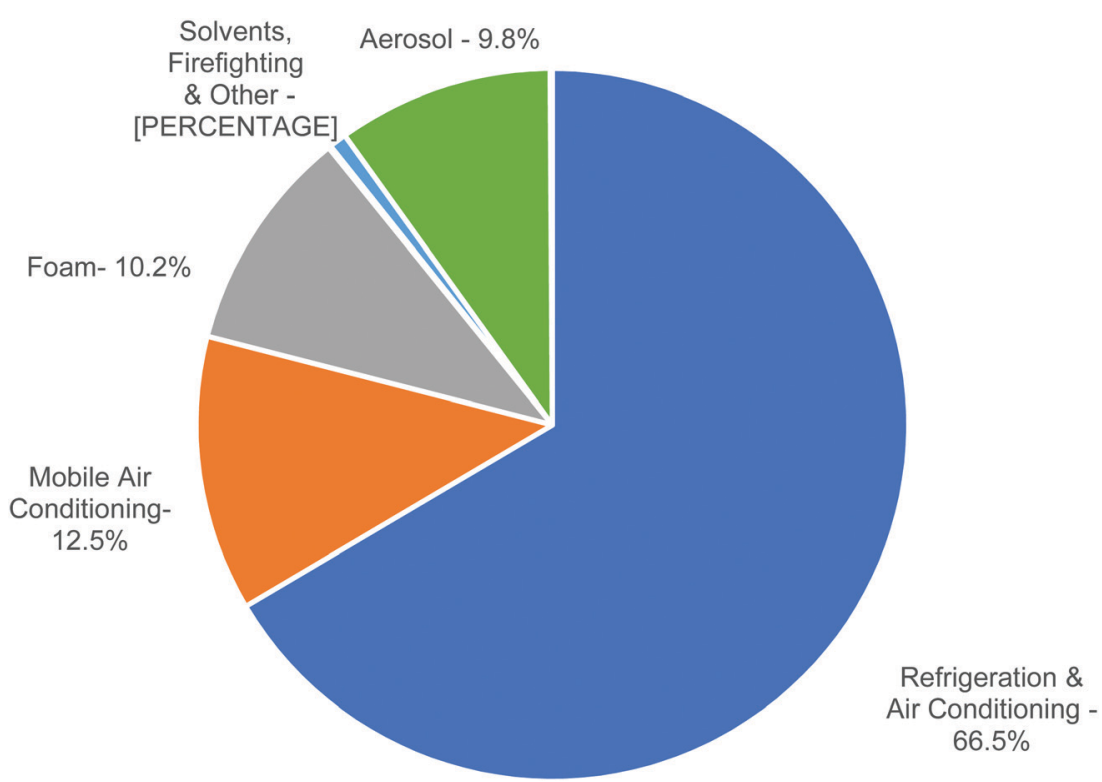

Fig. 2 Global Consumption of HFCs in 2015. (Data source: United Nations Environment Program (UNEP).)

Table 4 Typical applications of HCFCs and HFCs

\begin{tabular}{ll}
\hline Fluorocompound & Application field \\
\hline HCFC-22 (R22) & Residential air conditioning and refrigeration systems \\
HFC-134a (R134a) & $\begin{array}{l}\text { Domestic and commercial refrigeration systems } \\
\text { Mobile air conditioning systems (MACs) } \\
\text { Foam and MDIs } \\
\text { Propellants and aerosols }\end{array}$ \\
HFC-32 (R32) & Residential and commercial air conditioning systems \\
HFC-125 (R125) & Residential and commercial air conditioning systems (to prepare refrigerant blends of \\
& R410A, R407A, R407C, R404Aetc.) \\
HFC-143a (R143a) & Fire extinguishers \\
HFC-23 (R23) & Commercial and industrial refrigeration systems (to prepare refrigerant blends $e . g$. ., R404A) \\
R410A & Commercial and industrial refrigeration systems \\
R407C & Air conditioning applications \\
R404A & Air-conditioning applications \\
HFC-152a & Low temperature refrigeration applications \\
HFC-245fa & Industrial aerosol sector and extruded polystyrene foam
\end{tabular}


Table 5 Adsorption capacities of various fluorocarbons in different types of adsorbents at 1 bar and $298 \mathrm{~K}$

\begin{tabular}{|c|c|c|c|c|c|c|c|c|}
\hline Adsorbent & $\begin{array}{l}\text { BET surface } \\
\text { area }\left(\mathrm{m}^{2} \mathrm{~g}^{-1}\right)\end{array}$ & $\begin{array}{l}\text { Total pore } \\
\text { volume }\left(\mathrm{cm}^{3} \mathrm{~g}^{-1}\right)\end{array}$ & \multicolumn{5}{|c|}{ Adsorption amount $\left(\mathrm{mmol} \mathrm{g}^{-1}\right)$} & Ref. \\
\hline MAF-X10 $\left[\mathrm{Zn}_{4} \mathrm{O}(\mathrm{bpz})_{2}(\mathrm{bdc})\right]$ & 2032 & 0.798 & & $10.5^{a}$ & & & & 37 \\
\hline MAF-X13 $\left[\mathrm{Zn}_{4} \mathrm{O}(\mathrm{bpz})_{2}(\mathrm{bpdc})\right]$ & 2742 & 1.014 & & $13.5^{a}$ & & & & 37 \\
\hline MIL-101(Cr) & 2642 & 1.88 & 5 & 8.5 & $14^{f}$ & & 10.5 & 14 \\
\hline LIFM-26 & 1513 & 0.59 & & 6.5 & & & & 39 \\
\hline MIL-100(Fe) & - & - & & & & & 5.8 & 14 \\
\hline Ni-MOF-74 (BPP) & 2039 & 0.88 & & & $7.3^{f}$ & & 6.0 & 40 \\
\hline Ni-MOF-74 (TPP) & 1975 & 1.14 & & & $7.5^{f}$ & & & 40 \\
\hline Ni-MOF-74 (BPM) & 2340 & 1.01 & & & $6.9^{b f}$ & & & 43 \\
\hline Ni-MOF-74 (TPM) & 2420 & 1.49 & & & $13.7^{b f}$ & & & 43 \\
\hline MOFF-5 & 2445 & - & & & 5.4 & & 6.6 & 31 \\
\hline NU-1000(Zr) & 2259 & 1.58 & & & $17^{f}$ & & & 44 \\
\hline Activated carbon (BPL) & 1180 & 0.55 & & $4.6^{d}$ & & & $4.2^{d}$ & 47 \\
\hline Vruf carbon & 1330 & 0.81 & & & & 3.0 & & 48 \\
\hline Activated carbon powder & 3200 & 1.7 & $8.8^{e}$ & & & & & 49 \\
\hline Activated carbon fiber & 2200 & 1.0 & $6.9^{e}$ & & & & & 49 \\
\hline Fluka charcoal & 1143 & - & & & $3.25^{c}$ & & & 50 \\
\hline Maxsorb III & 3150 & 1.7 & & & 12.7 & & & 51 \\
\hline Silica gel & 750 & 0.35 & & 2.0 & 2.4 & & 2.0 & 52 \\
\hline
\end{tabular}

$\left[\mathrm{Zn}_{4} \mathrm{O}(\mathrm{bpz})_{2}(\mathrm{bpdc})\right], \mathrm{MIL}-101(\mathrm{Cr})$ and LIFM-26 have been studied. Since the molecular size of $\mathrm{R} 22(\approx 4.2 \AA)^{14}$ is smaller than the pore size of all these MOF adsorbents, the adsorption capacities of R22 in these materials can be fairly compared without considering the diffusion limitation. Among the MOF adsorbents, MAF-X13 exhibits the highest adsorption capacity of R22 followed by MAF-X10, MAF-X12, MIL-101(Cr) and LIFM-26 (Fig. 3). At 1 bar and $273 \mathrm{~K}$, isoreticular MAF-X10, MAF-X12 and MAF-X13 possess an R22 adsorption capacity of $10.5,9.5$, and $13.5 \mathrm{mmol} \mathrm{g}^{-1}$, respectively. ${ }^{37}$ MAF-X10 is isostructural with MOF- $5^{38}$ except that two thirds of the bdc linkers are substituted by the bpz linkers, forming a hydrophobic pore surface, which is beneficial for the adsorption of hydrophobic fluorocarbons. ${ }^{37}$ Its isostructural analogue MAF-X13 exhibits higher adsorption capacity than MAF-X10 mainly because of the difference in their cavity size and pore volume. Besides high adsorption capacity, they also show high thermal stability (MAF-X10 is stable at $550{ }^{\circ} \mathrm{C}$ while MAF-X12 and MAF-X13 are stable at $450{ }^{\circ} \mathrm{C}$ ), demonstrating their applicability in real time fluorocarbon capture processes.

Under similar operating conditions, high adsorption capacity of R22 (6.5 mmol g$\left.{ }^{-1}\right)$ in LIFM-26 (constructed from 2,3,5,6-tetrachloride terephthalic acid and $\left.\mathrm{Fe}_{3} \mathrm{O}\left(\mathrm{H}_{2} \mathrm{O}\right)_{3}\right)$, which is isostructural to MOF-235 and $\mathrm{Fe}_{3}\left(\mathrm{~F}_{4} \mathrm{BDC}\right)_{3}\left(\mathrm{H}_{2} \mathrm{O}\right)_{3}$, was also reported..$^{39}$ LIFM-26 consists of one type of tetrahedral cage $(7 \AA$ diameter) constructed from five $\mathrm{Fe}_{3} \mathrm{O}$ clusters and six tcdc ligands and two types of channels, each with different shapes (round and elliptic) and sizes (9 A diameter, $11.5 \times 6.5 \AA^{2}$, Fig. 1). Similar to MAF-X10 and MAF-X12, LIFM-26 also exhibits type I R22 adsorption. The steep gas uptake at low pressures is a characteristic of strong adsorbent-adsorbate affinity, in this case probably due to the existence of open metal sites and polar functional groups. Importantly, the adsorption enthalpy of R22 in LIFM-26 $\left(25 \mathrm{~kJ} \mathrm{~mol}^{-1}\right)$ is much lower than that in MAF-X series MOFs (31.4-32.9 $\mathrm{kJ} \mathrm{mol}^{-1}$ ), suggesting moderate adsorption affinity of R22 in LIFM-26, which should be beneficial for the adsorbent regeneration. Unfortunately, though LIFM-26 shows good water/chemical stability, it has only moderate thermal stability, which starts to collapse at temperatures above $200{ }^{\circ} \mathrm{C}$.

Recently, Motkuri et al., reported the adsorption of several fluorocarbons including R22, R32, R12, R13 and R14 in MIL101 , which is known for its extremely high surface area and large pore volume. ${ }^{14,41}$ At 1 bar and $298 \mathrm{~K}$, MIL-101 gives the highest uptake of R12 (10.5 mmol g $\left.\mathrm{g}^{-1}\right)$ followed by R22 $\left(8.5 \mathrm{mmol} \mathrm{g}^{-1}\right)$, R32 $\left(5 \mathrm{mmol} \mathrm{g}^{-1}\right)$, R13 $\left(2.4 \mathrm{mmol} \mathrm{g}^{-1}\right)$ and R14 $\left(<1 \mathrm{mmol} \mathrm{g}^{-1}\right)$. Besides MIL-101, the authors also studied the adsorption characteristics of R12 in MIL-100 (Fe), Co-MOF-74 and Ni-MOF-74. Both Co-MOF-74 and Ni-MOF-74 exhibit high adsorption capacities ( 4.5 and $5 \mathrm{mmol} \mathrm{g}^{-1}$, respectively) at the low pressure region $\left(P / P_{0}=0.01\right)$ and reach saturation at $P / P_{0}=0.05$, indicating strong interactions of R12 with the open metal sites in these MOFs. A recent work showed even higher R12 adsorption capacity $\left(6 \mathrm{mmol} \mathrm{g}^{-1}\right)$ in pore engineered Ni-BPP (BPP = 3,3'-dioxido-4,4'-biphenyldicarboxylate, biphenyl with para-COOH). Ni-BPP is an analogue of Ni-MOF- $74^{40}$ with the dobdc ${ }^{2-}$ linker substituted by BPP. The pore expanded Ni-BPP achieves higher surface area and pore volume than Ni-MOF-74, resulting in higher adsorption capacities than its parent counterpart (Fig. 4). The same study also reported high R134a adsorption capacity in Ni-MOF-74 and even higher R134a adsorption capacities in its pore expanded analogues: Ni-BPP 
(a)

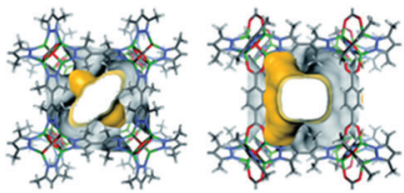

MAF-X10

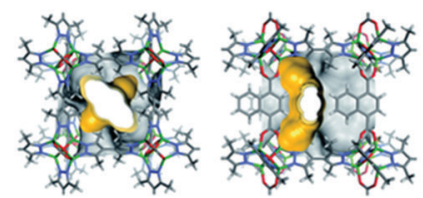

MAF-X12

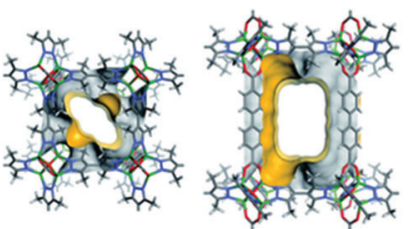

MAF-X13

(b)
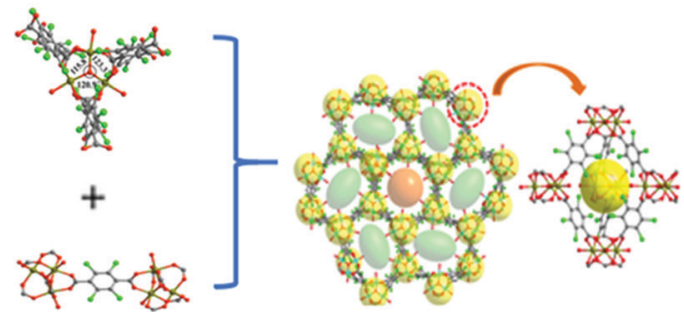

(c)

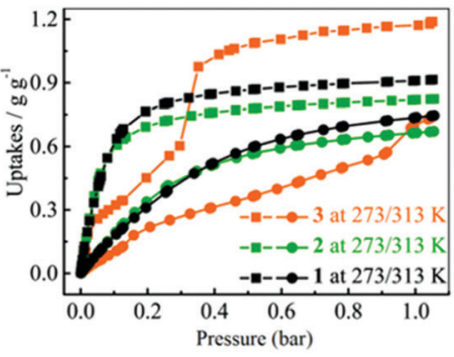

(d)

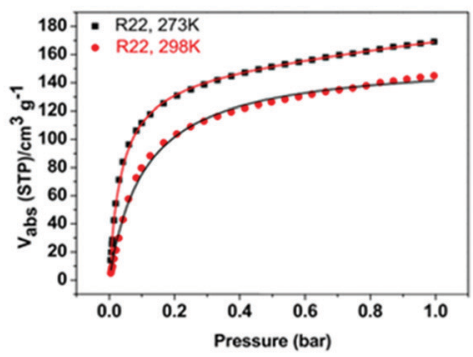

Fig. 3 (a) The pore structure of MAF-X10, MAF-X12 and MAF-X13 viewed along two characteristic directions. (b) The trimeric Fe 30 cluster, tcdc ${ }^{2-}$ coordination mode and packing diagram along the $c$ axis of LIFM-26. (c) and (d) R22 adsorption isotherms of MAF-X10, MAF-X12, MAF-X13 and LIFM-26, respectively. ${ }^{37,39}$ Reproduced from ref. 37 and 39 with permission from The Royal Society of Chemistry \& Wiley-VCH.

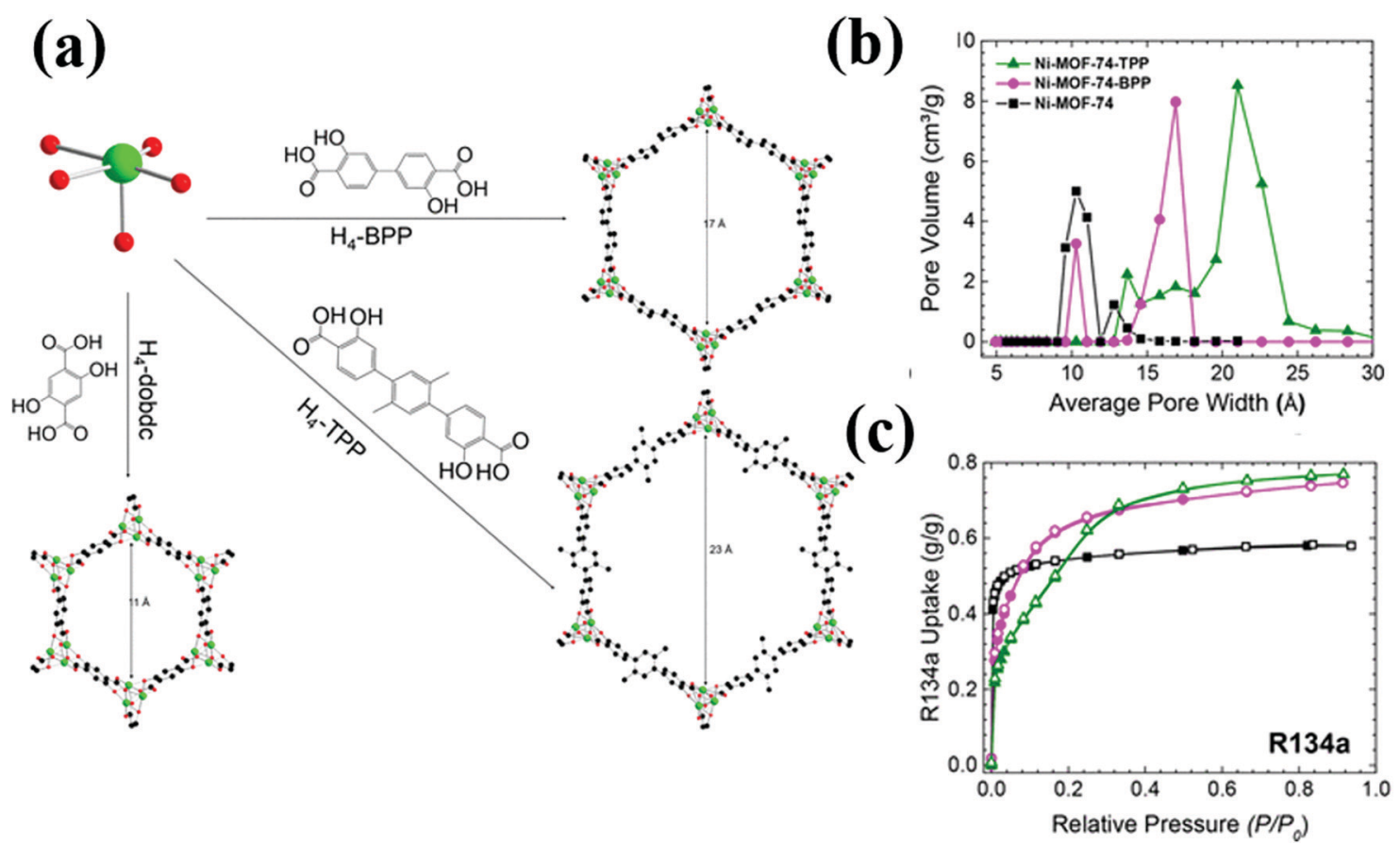

Fig. 4 (a) Schematic representation of the $\mathrm{Ni}^{2+}$ node, organic bridging ligands, and corresponding structures (viewed along the $\mathrm{C}$-axis) of the poreexpanded Ni-MOF-74 analogues. (b) Pore size distributions. (c) R134a pure gas adsorption isotherms at $298 \mathrm{~K}$; the black, magenta, and green curves correspond to Ni-MOF-4, Ni-BPP, and Ni-TPP, respectively. ${ }^{40}$ Reproduced from ref. 40 with permission from The Royal Society of Chemistry.

and N-TPP $\left(\mathrm{TPP}=3,3^{\prime}\right.$-dioxido-4, $4^{\prime}$-triphenyldicarboxylate, triphenyl with para-COOH).

All these MOF adsorbents show type I R134a adsorption, suggesting strong interaction of R134a with their pore surfaces. Though Ni-TPP exhibits the highest saturation capacity $\left(0.77 \mathrm{~g} \mathrm{~g}^{-1}\right)$ than its analogues: Ni-BPP $\left(0.75 \mathrm{~g} \mathrm{~g}^{-1}\right)$ and
Ni-MOF-74 $\left(0.58 \mathrm{~g} \mathrm{~g}^{-1}\right)$, the capacity difference of Ni-BPP and $\mathrm{Ni}$-TPP is only $0.02 \mathrm{~g} \mathrm{~g}^{-1}$. Ni-BPP has higher surface area than $\mathrm{Ni}$-TPP, leading to more sorbate-sorbent interaction. In Ni-TPP, though the surface area is smaller, its total pore volume is higher due to the three-phenylene rings, resulting in more adsorbate-adsorbent $(\mathrm{C}-\mathrm{F} \cdots \mathrm{M} / \mathrm{C}-\mathrm{H} \cdots \pi)$ interaction. 
A more recent research study ${ }^{43}$ reported R134a adsorption on two new pore expanded analogues of Ni-MOF-74, which were synthesized by adjusting the relative locations of the hydroxyland carboxylate moieties in the dihydroxyterephthalic acid ligands with 2 to 3 phenylene rings named as Ni-TPM $\left(4,4^{\prime \prime}-\right.$

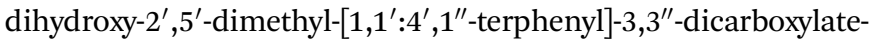
"meta") and Ni-BPM (bi-phenyl-"meta"). Ni-TPM in particular shows immense R134a uptake at high pressures with a saturation capacity of more than $1.4 \mathrm{~g} \mathrm{~g}^{-1}(\sim 300 \%$ increase compared to Ni-MOF-74). The GCMC simulations show that R134a initially sits in the vicinity of the nickel node of the framework. With increase in pressure, the fluorocarbon forms a monolayer at the vicinity of the pore wall interacting with both the inorganic node and the organic linker of the MOF followed by pore filling at high pressures. This study further reported the atomic level interaction of fluorocarbon molecules with the MOF pore surface. The DFT-optimized geometry reveals that the very initial stage of adsorption involves an interaction between the fluorine of R134a and the Ni-open metal sites in the MOF surface. R134a consists of two fluorine containing branches, one with $\mathrm{CF}_{3}$ and the other with $\mathrm{CH}_{2} \mathrm{~F}$. The results suggest that the $\mathrm{CH}_{2} \mathrm{~F}$ moiety of R134a rather than the $\mathrm{CF}_{3}$ moiety interacts with the metal node of the MOF.

Zheng et al.,${ }^{44}$ reported R134a adsorption characteristics of a few well-studied MOFs: NU-1000(Zr), NU-901(Zr), PCN-222(Zr), MIL-101(Cr), and MOF-74TPP(Ni). Among these, the R134a adsorption capacity is the highest in NU-1000(Zr) (170 wt\%) upon saturation compared to NU-901(Zr) (135 wt\%), PCN-22(Zr) (130 wt\%) and MIL-101(Cr) (140 wt\%).

Another recent study ${ }^{53}$ reported R134a adsorption characteristics in Ni-MOF-74 and MIL-101(Cr). Both experimental and simulated R134a adsorption isotherms exhibit type I adsorption behaviour. Ni-MOF-74 is shown to reach saturation at much lower pressures than Cr-MIL-101. This can be attributed to the high affinity unsaturated coordination sites on the metal node, which are available in activated Ni-MOF-74 but not in Cr-MIL-101. Upon saturation, the adsorption capacity of MIL$101(\mathrm{Cr})$ is around $140 \mathrm{wt} \%$, which is nearly three times more than that of Ni-MOF-74 $(\sim 58 \mathrm{wt} \%)$. The computed radial distribution functions (RDFs) between framework atoms and different atoms of R134a suggest that the metal sites of both MOFs are more preferable adsorption sites toward R134a than the linker atoms because of the favourable C-F $\cdots \mathrm{M}^{+}$interactions between the negatively charged fluorine atoms of R134a and the positively charged metal atoms.

Chen et al., ${ }^{31}$ recently revealed the second highest R12 $\left(6.6 \mathrm{mmol} \mathrm{g}^{-1}\right)$ adsorption capacity in MOFF-5 (Fig. 5). Reaction of a tetrazole-based ligand (Fig. 3a) with $\mathrm{CuCl}_{2} \cdot 2 \mathrm{H}_{2} \mathrm{O}$ in a mixture of $N, N$-diethylformamide (DEF), methanol and water formulates MOFF-5 with a three-dimensional network: $\left[\mathrm{Cu}\left(\mathrm{H}_{2} \mathrm{O}\right)_{6}\right]_{1.5}\left[\left(\mathrm{Cu}_{4} \mathrm{Cl}\right)_{3}\left(2-3 \mathrm{H}^{+}\right)^{8}\left(\mathrm{H}_{2} \mathrm{O}\right)_{12}\right]$. Other than for R12 and R134a, this material also shows high adsorption capacities for HFC-227ea, CFC-113, HCFC-225ca, perfluorohexane and dichloromethane. But, it exhibits poor $\mathrm{SF}_{6}$ and R14 adsorption capacities. The authors tentatively rationalized the poor adsorption capacities based on the low polarities of these guest

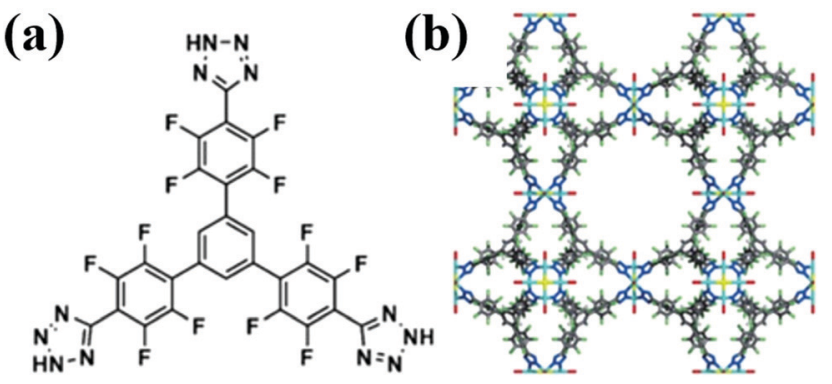

Fig. 5 (a) Extensively fluorinated tritopic MOF precursor (2) and (b) synchrotron X-ray crystal structure of MOFF-5. ${ }^{31}$ Reproduced from ref. 31 with permission from Wiley-VCH.

molecules, which mismatched with the highly polarized environment inside the fluorinated cavities, though there was not an overall correlation between the dipole moment and the adsorption capacity within MOFF- 5 . The poor stability to water and moisture appear to be the major disadvantages for the applicability of MOFF-5 in fluorocompound capture and separation.

To achieve efficient fluorocarbon separation, the MOF adsorbents can be selected based on their (1) molecular sieving effect, which is based upon size/shape exclusion of certain components in a gas mixture; (2) thermodynamic equilibrium effect, due to difference in adsorption affinities; and (3) kinetic effect, due to difference in diffusion of different components in a gas mixture. In this regard, information on molecular size, polarizability, and dipole moment of the gases in the mixture that need to be separated is extremely important. Table 6 lists these properties of various fluorocarbons.

Among the available literature on fluorocarbon adsorption in MOFs, only Motkuri et al., detailed the fluorocarbon separation (Fig. 6). ${ }^{14}$ With the aid of experimental and simulated column breakthrough results, the authors showed thermodynamic equilibrium separation of fluorocarbon blends containing R12, R14, R32, R22, and R12 in MIL-101 based on different polarizabilities (Table 6). Generally speaking, for selectivity based on a physisorptive adsorption mechanism, the separation relies on the gas molecules having different physical properties, such as polarizability or quadrupole moment, resulting in a higher enthalpy of adsorption for certain gas molecules over the others.

Following the order of adsorption capacity, the simulated breakthrough results indicate early breakthrough of R14 through the column filled with MIL-101 followed by R13, R32, R12 and

Table 6 Physical properties of some common fluorocarbons

\begin{tabular}{lllll}
\hline & $\begin{array}{l}\text { Kinetic } \\
\text { diameter/A }\end{array}$ & $\begin{array}{l}\text { Boiling } \\
\text { point/K }\end{array}$ & $\begin{array}{l}\text { Polarizability } \\
(\alpha) / \mathrm{cm}^{3} \mathrm{~mol}^{-1}\end{array}$ & $\begin{array}{l}\text { Dipole } \\
\text { moment/ } \\
\text { Debye }\end{array}$ \\
\hline $\mathrm{R} 12\left(\mathrm{CCl}_{2} \mathrm{~F}_{2}\right)$ & 4.4 & 243.2 & - & 0.51 \\
$\mathrm{R} 13\left(\mathrm{CClF}_{3}\right)$ & 4.5 & 191.5 & - & 0.50 \\
$\mathrm{R} 22\left(\mathrm{CHClF}_{2}\right)$ & 4.2 & 232.1 & - & 1.42 \\
$\mathrm{R} 32\left(\mathrm{CH}_{2} \mathrm{~F}_{2}\right)$ & 3.9 & 221.3 & 13.2 & 1.97 \\
$\mathrm{R} 125\left(\mathrm{CHF}_{2} \mathrm{CF}_{3}\right)$ & 4.4 & 224.9 & 14.3 & 1.54 \\
$\mathrm{R} 134 \mathrm{a}\left(\mathrm{CH}_{2} \mathrm{FCF}_{3}\right)$ & - & 246.9 & 13.8 & 2.06 \\
$\mathrm{R} 143 \mathrm{a}\left(\mathrm{CH}_{3} \mathrm{CF}_{3}\right)$ & - & 225.8 & 14.4 & 2.32
\end{tabular}


(a)

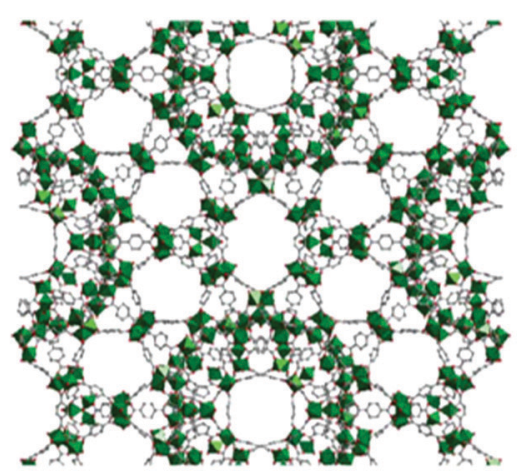

(c)

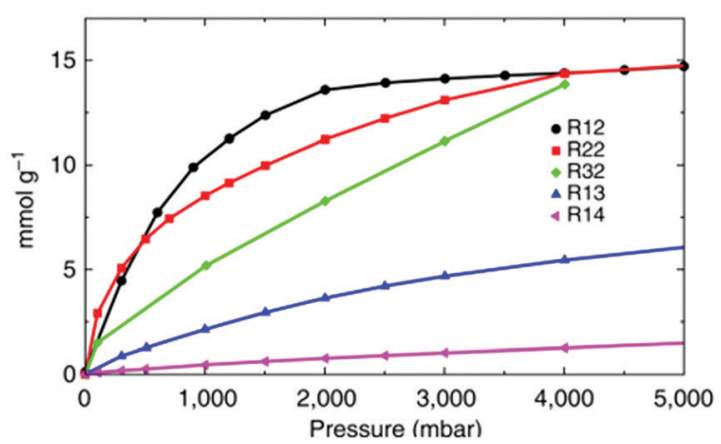

(b)

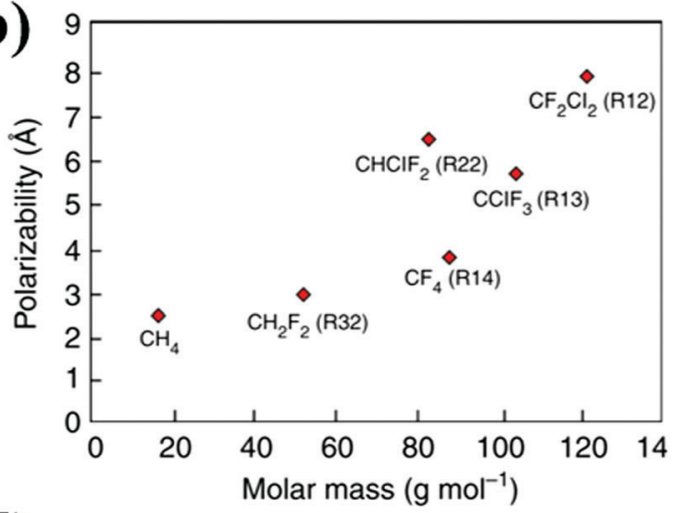

(d)

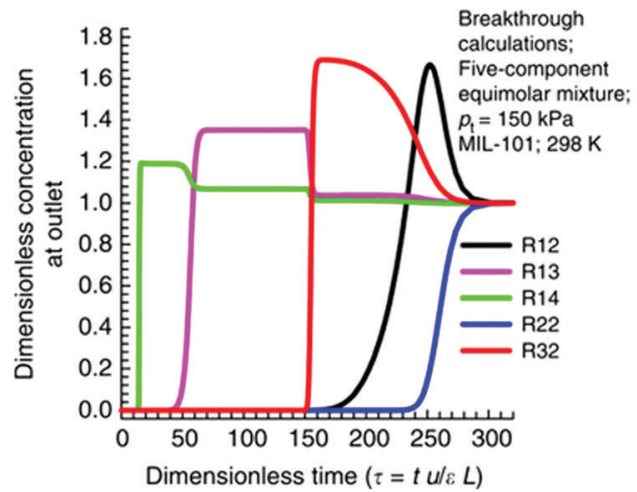

Fig. 6 (a) Crystal structure of MIL-101. (b) Physical properties of various fluorocarbons. (c) Sorption profiles of various fluorocarbon refrigerants in MIL101 at 298 K. (d) Simulated breakthrough characteristics of an adsorption column packed with MIL-101 for a mixture of equimolar R12/R22/R13/R14/ R32. ${ }^{14}$ Reproduced from ref. 14 with permission from Springer Nature.

R22, respectively. Although R13 and R14 have higher polarizability than R32, they show earlier breakthrough than R32. R32 has lower molar mass and molecular size as compared to R13 and $\mathrm{R} 14$, which thus promotes its efficient packing within the pores of MIL-101, resulting in higher adsorption capacity.

MOFs with open metal sites create strong electrostatic interactions with the gas molecules, and therefore substantial gas selectivity can be achieved based on the differences in polarizabilities and dipole moments of the gases in the mixture. However, in the case of fluorocarbon separation, irrespective of the differences of their polarizabilities, the possible formation of strong open metal site M $\cdots$ F electrostatic interaction may adversely influence their degree of gas selectivity. For example, LIFM-26 and M-MOF-74 with open metal sites show steep fluorocarbon uptakes at low pressures, which is more pronounced as compared to that in MIL-101, suggesting stronger fluorocarbon affinity to open metal sites. ${ }^{54}$ Such strong fluorocarbon interactions with pore surfaces often result in high adsorption capacities but at the same time they adversely reduce the adsorption selectivity, which is not beneficial for gas separation, especially when high product purity is needed.

Besides utilization of MOFs for the separation of fluorocompounds via thermodynamic equilibrium effect, the possible kinetic and steric separation based on the differences in gas molecular sizes (Table 6) has not yet been explored. However, there exist numerous literature reports on the separation of small molecules over ultramicroporous molecular sieve MOFs. For example, $\mathrm{Mn}(\mathrm{HCOO})_{2}$ (Fig. 7a), a porous framework containing cages with a diameter of about $5.5 \AA$ connected to each other via small windows of about $4.5 \AA$, showed higher selectivity for $\mathrm{CO}_{2}$ over other larger molecules $\left(\mathrm{N}_{2}, \mathrm{O}_{2}, \mathrm{Ar}\right.$, and etc.) because of the steric effect. ${ }^{55}$ SIFSIX-3-Zn is another MOF (Fig. 7b) constructed from short building blocks, forming ultra-small pore diameter, which is suitable for steric separation of small gas molecules. ${ }^{56}$ It is isostructural to SIFSIX-1-Cu except that the relatively long ligand $4,4^{\prime}$-bipyridine in SIFSIX-1$\mathrm{Cu}$ is replaced by shorter pyrazine in SIFSIX-3-Zn, and $\mathrm{Cu}(\mathrm{II})$ is replaced by $\mathrm{Zn}(\mathrm{II})$. The reduction in ligand length leads to a contracted pore aperture of SIFSIX-3-Zn (3.84 ̊̊) versus SIFSIX-1$\mathrm{Cu}(9.54 \AA)$. Doubly interpenetrated SIFSIX-2-Cu-i (isostructural to SIFSIX-2-Cu) constructed using $\mathrm{CuSiF}_{6}$ and 4,4'-dipyridylacetylene possesses smaller pore size of $5.15 \AA$ as compared to 13.05 Å in SIFSIX-2-Cu, which also showed good performance in small gas molecule separation. Though these types of MOFs are suitable for steric separation of fluorocarbons, their low surface area and small pore volume significantly limit their adsorption capacities. Therefore, design/selection of molecular sieve MOFs with high selectivity and adsorption capacity is still very challenging and needs to be explored to a greater extent. 
(a)

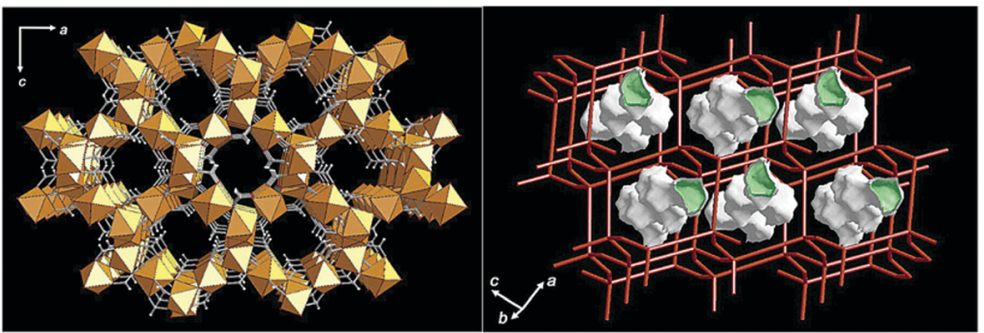

(b)

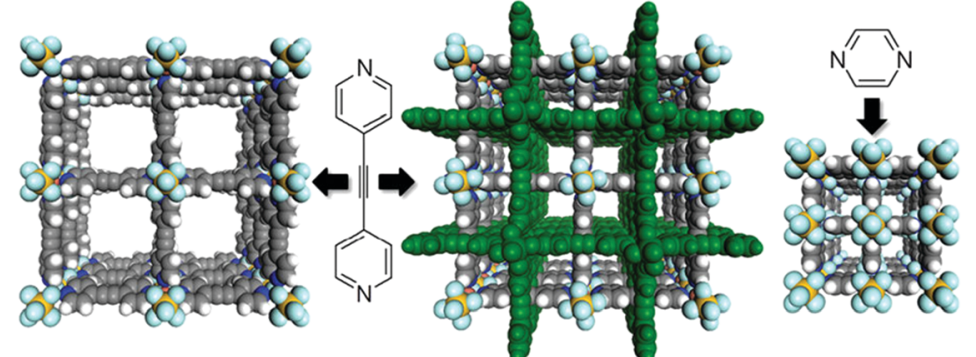

SIFSIX-2-Cu; pore size $13.05 \AA$

SIFSIX-2-Cu-i; pore size $5.15 \AA \quad$ SIFSIX-3-Zn; pore size $3.84 \AA$

Fig. 7 (a) X-ray crystal structure and crystal topology of $\mathrm{Mn}(\mathrm{COO})_{2}{ }^{55}$ (b) Structures of SIFSIX-Cu, interpenetrated SIFSIX-Cu-i and pore contracted SIFSIX-3-Zn. ${ }^{55,57}$ Reproduced from ref. 55 and 57 with permission from The Royal Society of Chemistry \& Springer Nature.

\section{Advantages of MOFs over conventional adsorbents for fluorocompound separation}

To consider MOFs for the adsorption based separation of fluorocompounds, several specific attributes such as adsorption capacity and selectivity for the target molecules, energy requirement for regeneration, stability and reusability need to be carefully evaluated.

During our earlier studies, we have successfully utilized conventional zeolites for the separation of R32, R22, R125, R134a and R143a. ${ }^{45,46}$ Those separations were achieved based on molecular sieving behaviour. However, when comparing the adsorption capacities of zeolites (Tables 2 and 5) with MOFs, a clear difference can be observed. The adsorption capacities of MOFs are much higher owing to their much larger specific surface areas and pore volumes. For example, the capacity of R134a adsorption in $13 \mathrm{X}$ zeolite is only $2.7 \mathrm{mmol} \mathrm{g}^{-1}$ while it is $5.7 \mathrm{mmol} \mathrm{g}^{-1}, 7.3 \mathrm{mmol} \mathrm{g}^{-1}$, and $7.5 \mathrm{mmol} \mathrm{g}^{-1}$ in Ni-MOF-74, Ni-MOF-74(BPP), and Ni-MOF-74(TPP), respectively.

To achieve continuous gas separation, the adsorbent after reaching saturation in gas adsorption has to be regenerated. An ideal adsorbent regeneration process should minimize the energy input to remove the major fraction of adsorbed gas molecules as well as should retain the adsorption performance during repeated regeneration cycles. A recent study ${ }^{58}$ reported $70 \%$ and $73.3 \%$ regenerability of UiO-66 for R22 and R125 at $373 \mathrm{~K}$ while it is only $22.4 \%$ and $30.3 \%$ in $13 \mathrm{X}$ zeolite.

Very high R32 and R134a adsorption capacities are reported in several types of activated carbons (activated carbon powder (ACP), activated carbon fiber (ACF), Maxsorb III) thanks to their exceptionally high surface areas and pore volumes. ACP exhibits the highest R32 adsorption capacity of $8.8 \mathrm{mmol} \mathrm{g}^{-1}$ (measured at $297.2 \mathrm{~K}$ and 2 bar) and Maxsorb III which possesses extremely high surface area and pore volume (surface area and pore volume are $3150 \mathrm{~m}^{2} \mathrm{~g}^{-1}$ and $1.7 \mathrm{~cm}^{3} \mathrm{~g}^{-1}$, respectively) displays the highest R134a adsorption capacity $\left(12.7 \mathrm{mmol} \mathrm{g}^{-1}\right)$. However, unlike molecular sieve zeolite and MOFs, which have uniform pore structures, activated carbon has a wide pore range from micropore to macropore, making the utilization of activated carbon for molecular sieve separation extremely difficult. So in terms of adsorption capacity, selectivity and regenerability, MOFs outperform traditional adsorbents in fluorocarbon separation.

\section{Conclusions and future perspectives}

In summary, we have discussed the recent progress made in the investigation of metal organic frameworks for the adsorptionbased capture and separation of various fluorocompounds. In these investigations, the high fluorocompound adsorption capacity of MOFs compared to traditional adsorbents is quite distinguishable. However, the working capacity, adsorption selectivity and regeneration are more important decisive factors than the absolute adsorption capacity since those factors decide the overall efficiency of the process and those are not studied in detail so far. Most of the investigations have primarily focused on exploring new MOFs using single component adsorption properties, from which selectivities are calculated by applying Ideal Adsorption Solution Theory (IAST). Though these practices are acceptable for initial performance evaluations, their selectivities, regenerabilities and cyclic working capacities should be studied using more accurate and practically realistic methods. For example, the selectivities of MOFs for separation of various fluorocompound mixtures relevant to their different compositions should be assessed via 
practically realistic breakthrough experiments so that their potential for large-scale applications can be verified.

Besides these performance evaluation factors, the chemical, thermal and mechanical stability of the MOFs also need to be considered since those are critical to adsorbent inventory and eventually to the economic feasibility of the process. Furthermore, prospects of candidate MOFs for large scale synthesis should be assessed considering the cost of starting materials, impacts of waste products on the environment etc. in order to use them in commercial fluorocompound capture and separation applications.

\section{Nomenclature}

$\begin{array}{ll}\text { CFC } & \text { Chlorofluorocarbon } \\ \text { HCFC } & \text { Hydrochlorofluorocarbons } \\ \text { HFC } & \text { Hydrofluorocarbon } \\ \text { PFC } & \text { Perfluoro compound } \\ \text { R32 } & \mathrm{CH}_{2} \mathrm{~F}_{2} \\ \text { R12 } & \mathrm{CCl}_{2} \mathrm{~F}_{2} \\ \text { R13 } & \mathrm{CClF}_{3} \\ \text { R22 } & \mathrm{CHClF}_{2} \\ \text { R125 } & \mathrm{CHF}_{2} \mathrm{CF}_{3} \\ \text { R134a } & \mathrm{CH}_{2} \mathrm{FCF}_{3} \\ \text { R143a } & \mathrm{CH}_{3} \mathrm{CF}_{3} \\ \text { R152a } & \mathrm{CH}_{3} \mathrm{CHF}_{2} \\ \mathrm{H}_{2} \text { bdc } & 1,4-\mathrm{Benzene}^{\prime} \text { dicarboxylic acid } \\ \mathrm{H}_{2} \text { bpz } & 3,3^{\prime}, 5,5^{\prime} \text {-Tetramethyl-4,4'-bipyrazole } \\ \mathrm{H}_{2} \text { ndc } & \text { Naphthalene-1,4-dicarboxylic acid } \\ \mathrm{H}_{2} \text { bpdc } & \text { Biphenyl-4,4'-dicarboxylic acid } \\ \mathrm{H}_{2} \text { tcdc } & 2,3,5,6 \text {-Tetrachloride terephthalic acid } \\ \text { H }{ }_{3} \text { btb } & \text { Benzene-1,3,5-tribenzoic acid } \\ \text { H }{ }_{3} \text { btc } & \text { Benzene-1,3,5-tricarboxylic acid } \\ \text { dabco } & \text { 1,4-Diazabicyclo[2.2.2] octane } \\ \text { Hdmcpz } & \text { 3,5-DimethoxycarbonyIpyrazole. } \\ & \end{array}$

\section{Conflicts of interest}

There are no conflicts to declare.

\section{References}

1 N. A. Lai, Appl. Therm. Eng., 2014, 70, 1.

2 S. S. Murthy and D. D. Phuong, Int. J. Energy Res., 1989, $13,1$.

3 M. J. Molina and F. S. Rowland, Rev. Geophys., 1975, 13, 1.

4 R. J. Salawitch, Encyclopedia of the Anthropocene, 2018, 33-41.

5 B. Xiang, P. K. Patra, S. A. Montzka, S. M. Miller, J. W. Elkins, F. L. Moore, E. L. Atlas, B. R. Miller, R. F. Weiss, R. G. Prinn and S. C. Wofsy, Proc. Natl. Acad. Sci. U. S. A., 2014, 111, 17379.

6 H. Tatsuya, I. Hisashi, M. Ryuji and Y. Yoshikuni, Appl. Energy, 2001, 72, 705.

7 P. Makhnatch, A. Mota-Babiloni, J. Rogstam and R. Khodabandeh, Int. J. Refrig., 2017, 76, 184.
8 G. G. Haselden, Gas Sep. Purif., 1989, 3, 209.

9 J. R. Li, J. Sculley and H. C. Zhou, Chem. Soc. Rev., 2012, 112, 869.

10 L. Li, S. Tang, C. Wang, X. Lv, M. Jiang, H. Wu and X. Zhao, Chem. Commun., 2014, 50, 2304.

11 A. M. Fracaroli, H. Furukawa, M. Suzuki, M. Dodd, S. Okajima, F. Gandara, J. A. Reimer and O. M. Yaghi, J. Am. Chem. Soc., 2014, 136, 8863.

12 M. Zhao, Y. Wang, Q. Ma, Y. Huang, X. Zhang, J. Ping, Z. Zhang, Q. Lu, Y. Yu, H. Xu, Y. Zhao and H. Zhang, Adv. Mater., 2015, 27, 7372.

13 P. Xydias, I. Spanopoulos, E. Klontzas, G. E. Froudakis and P. N. Trikalitis, Inorg. Chem., 2014, 53, 679.

14 R. K. Motkuri, H. V. R. Annapureddy, M. Vijaykumar, H. T. Schaef, P. F. Martin, B. P. McGrail, L. X. Dang, R. Krishna and P. K. Thallapally, Nat. Commun., 2014, 5.

15 J. Jiang, H. Furukawa, Y. B. Zhang and O. M. Yaghi, J. Am. Chem. Soc., 2016, 138, 10244.

16 T. Rodenas, I. Luz, G. Prieto, B. Seoane, H. Miro, A. Corma, F. Kapteijn, F. X. Llabres i Xamena and J. Gascon, Nat. Mater., 2015, 14, 48.

17 K. Manna, P. Ji, F. X. Greene and W. Lin, J. Am. Chem. Soc., 2016, 138, 7488.

18 M. I. Gonzalez, E. D. Bloch, J. A. Mason, S. J. Teat and J. R. Long, Inorg. Chem., 2015, 54, 2995.

19 F. Carson, S. Agrawal, M. Gustafsson, A. Bartoszewicz, F. Moraga, X. Zou and B. Martin-Matute, Chemistry, 2012, 18, 15337.

20 Z. Q. Li, A. Wang, C. Y. Guo, Y. F. Tai and L. G. Qiu, Dalton Trans., 2013, 42, 13948.

21 Y. Wang, Y. Lu, W. Zhan, Z. Xie, Q. Kuang and L. Zheng, J. Mater. Chem. A, 2015, 3, 12796.

22 H. Furukawa, K. E. Cordova, M. O’Keeffe and O. M. Yaghi, Science, 2013, 341, 1230444.

23 M. B. Chang and J.-S. Chang, Ind. Eng. Chem. Res., 2006, 45, 4101.

24 W. Walter, P. Phyllis, K. Ray and M. Laurie, Analysis of Data for Perfluorocompound (PFC) Emission Control Systems, 2012.

25 M.-B. Kim, S.-J. Lee, C. Y. Lee and Y. S. Bae, Microporous Mesoporous Mater., 2014, 190, 356.

26 I. Senkovska, F. Hoffmann, M. Fröba, J. Getzschmann, W. Böhlmann and S. Kaskel, Microporous Mesoporous Mater., 2012, 156, 115.

27 P. Chowdhury, C. Bikkina, D. Meister, F. Dreisbach and S. Gumma, Microporous Mesoporous Mater., 2009, 117, 406.

28 C. Y. Chuah and T.-H. Bae, J. Phys. Chem. C, 2017, 121(12), 6748.

29 P.-J. Kim, Y.-W. You, H. Park, J.-S. Chang, Y.-S. Bae, C.-H. Lee and J.-K. Suh, Chem. Eng. J., 2015, 262, 683.

30 P. Chowdhury, C. Bikkina and S. Gumma, J. Phys. Chem. C, 2009, 113, 6616.

31 T.-H. Chen, I. Popov, W. Kaveevivitchai, Y.-C. Chuang, Y.-S. Chen, A. J. Jacobson and O. S. Miljanic, Angew. Chem., 2015, 54, 13902.

32 M.-B. Kim, T.-U. Yoon, D.-Y. Hong, S.-Y. Kim, S.-J. Lee, S.-I. Kim, S.-K. Lee, J.-S. Chang and Y.-S. Bae, High SF6/N2 selectivity in a hydrothermally stable zirconium-based metal-organic framework, Chem. Eng. J., 2015, 276, 315. 
33 N.-G. Ahn, B.-H. Min and S.-S. Suh, J. Chem. Eng. Data, 2006, 51, 451.

34 W.-S. Cho, K.-H. Lee, H.-J. Chang, W. Huh and H.-H. Kwon, Korean J. Chem. Eng., 2011, 28(11), 2196.

35 M. A. Alkhabbaz, P. Bollini, G. S. Foo, C. Sievers and C. W. Jones, J. Am. Chem. Soc., 2014, 136(38), 13170.

36 J. R. Li, R. J. Kuppler and H. C. Zhou, Chem. Soc. Rev., 2009, 38(5), 1477.

37 R.-B. Lin, T.-Y. Li, H.-L. Zhou, C.-T. He, J.-P. Zhang and X.-M. Chen, Chem. Sci., 2015, 6(4), 2516.

38 M. E. Hailian Li, M. O'Keeffe and O. M. Yaghi, Nature, 1991, 402.

39 C. X. Chen, S. P. Zheng, Z. W. Wei, C. C. Cao, H. P. Wang, D. Wang, J. J. Jiang, D. Fenske and C. Y. Su, Chemistry, 2017, 23, 4060 .

40 J. Zheng, R. S. Vemuri, L. Estevez, P. K. Koech, T. Varga, D. M. Camaioni, T. A. Blake, B. P. McGrail and R. K. Motkuri, J. Am. Chem. Soc., 2017, 139(31), 10601.

41 G. Ferey, C. Mellot-Draznieks, C. Serre, F. Millange, J. Dutour, S. Surble and I. Margiolaki, Science, 2005, 309(5743), 2040.

42 H. V. R. Annapureddy, R. K. Motkuri, P. T. M. Nguyen, T. B. Truong, P. K. Thallapally, B. P. McGrail and L. X. Dang, Mol. Simul., 2014, 40, 571.

43 J. Zheng, D. B. Benjamin, A. Trump, M. Shetty, Y. Fan, P. Bhattacharya, J. J. Jenks, C.-Y. Su, C. M. Brown, G. Maurin, P. McGrail and R. K. Motkuri, J. Am. Chem. Soc., 2020, 142(6), 3002.

44 J. Zheng, D. Barpaga, O. Y. Gutiérrez, N. D. Browning, B. L. Mehdi, O. K. Farha, J. A. Lercher, B. P. McGrail and R. K. Motkuri, Exceptional Fluorocarbon Uptake with Mesoporous Metal-Organic Frameworks for Adsorption-Based Cooling Systems, ACS Appl. Energy Mater., 2018, 1, 5853-5858.
45 D. K. J. A. Wanigarathna, B. Liu and J. Gao, AIChE J., 2018, 64(2), 640.

46 D. J. A. Wanigarathna, J. Gao, T. Takanami, Q. Zhang and B. Liu, ChemistrySelect, 2016, 1, 3718.

47 K. Berlier and J. Bougard, J. Chem. Eng. Data, 1995, 40(5), 1137.

48 Y. Peng, X. Zheng, H. Wang, C. Xu, Q. Xiao, Y. Zhong and W. Zhu, Ind. Eng. Chem. Res., 2010, 49, 10009.

49 A. A. Askalany, B. B. Saha, K. Uddin, T. Miyzaki, S. Koyama, K. Srinivasan and I. M. Ismail, J. Chem. Eng. Data, 2013, 58, 2828.

50 B. S. Akkimaradi, M. Prasad, P. Pradip Dutta and K. Srinivasan, J. Chem. Eng. Data, 2001, 46, 417.

51 W. S. Loh, A. B. Ismail, B. Xi, K. C. Ng and W. G. Chun, J. Chem. Eng. Data, 2012, 57, 2766.

52 K. B. Marc Frere, J. Bougard and R. Roger Jadot, J. Chem. Eng. Data, 1994, 39, 697.

53 D. Barpaga, B. K. Medasani, S. Chatterjee, B. P. McGrail, R. K. Motkuri and L. X. Dang, Sci. Rep., 2018, 09.

54 E. D. Bloch, W. L. Queen, R. Krishna, J. M. Zadrozny, C. M. Brown and J. R. Long, Science, 2012, 335, 1606.

55 Danil N. Dybtsev, H. C. Sun Hong Yoon, Dongwoo Kim and Kimoon Kim, J. Am. Chem. Soc., 2004, 126.

56 K. Uemura, A. Maeda, T. K. Maji, P. Kanoo and H. Kita, Eur. J. Inorg. Chem., 2009, (16), 2329-2337.

57 P. Nugent, Y. Belmabkhout, S. D. Burd, A. J. Cairns, R. Luebke, K. Forrest, T. Pham, S. Ma, B. Space, L. Wojtas, M. Eddaoudi and M. J. Zaworotko, Nature, 2013, 495(7439), 80-84.

58 J. A. D. K. Wanigarathna, J. Gao and B. Liu, Chem. - Asian J., 2018, 13, 977-981. 